\title{
Benzothiadiazole (BTH) induces resistance to Pepper golden mosaic virus (PepGMV) in pepper (Capsicum annuum L.)
}

\author{
Trejo-Saavedra D.L., García-Neria M.A., Rivera-Bustamante R.F.' \\ * Centro de Investigación y de Estudios Avanzados del IPN (Cinvestav) - Unidad Irapuato. Departamento de Ingeniería Genética. Km 9.6 Libramiento Norte, Irapuato, \\ Guanajuato, Mexico 36821
}

\section{SUMMARY}

Pepper is an economically important crop in many countries around the world but it is susceptible to many diseases. In Mexico, diseases caused by bipartite begomoviruses have emerged as important problems in pepper. Several control strategies have been explored wiht little success; most of them are based on the avoidance of virus transmission and the breeding for resistance. Abiotic inducers can act at various points in the signaling pathways involved in disease resistance, providing long-lasting, wide-spectrum resistance. Benzothiadiazole (BTH) shares the property of activating the systemic acquired resistance pathway downstream from the SA signaling. In this work, resistance to PepGMV infection was induced in pepper plants by activating the SA pathway using BTH treatment. The resistance was characterized by evaluating symptom appearance, virus accumulation and viral movement. Our results showed that BTH could be an attractive alternative to induce geminivirus resistance in pepper plants without a significant damage of the fruit quality and productivity.

Key words: Geminivirus, systemic acquired resistance, induced resistance, BTH.

\section{INTRODUCTION}

Pepper (Capsicum annuum L.) is an economically important crop in many countries around the world. Pepper production in Mexico in 2011 was approximately 2,100,000 tons ((SIAP-SAGARPA), 2012). In addition to its economic relevance, in Mexico pepper is considered part of its cultural and social identity.

There are four Capsicum species cultivated in Mexico: C. annuum L., C. pubescens R. \& P., C. chinense Jacq. and C. frutescens L. C. annuum is by far the most important species, since it includes many types of economically important pepper types (jalapeños, anchos, serranos, pasillas, coras, costeños, etc.). Pepper crops are susceptible to many diseases, including those caused by RNA viruses such as Tobacco etch virus (TEV), Tobacco mosaic virus (TMV), Cucumber mosaic virus (CMV), and DNA viruses such as the geminiviruses Pepper golden mosaic virus (PepGMV) and Pepper huasteco yellow vein virus (PHYVV) (Méndez-Lozano et al., 2003; Torres-Pacheco et al., 1996).

The family Geminiviridae includes a large number of single-stranded DNA viruses with a genome contained in one or two components (Rojas et al., 2005). The genus Begomovirus is currently the largest in the family and the number of accepted species increasing rapidly, from 117 in 2005 to 181 in 2008 (Fauquet et al., 2008; Fauquet and Stanley, 2005). Begomoviruses are transmitted by whiteflies (Bemisia tabaci Genn.); they are widely distributed around the world and cause economically important diseases in many crops (Moffat, 1999; Morales and Anderson, 2001; Varma and Malathi, 2003). In Mexico, diseases caused by bipartite begomoviruses such as PepGMV and PHYVV have emerged as important problems in pepper and other economically important and related crops such as tomato, tomatillo and tobacco (Holguín-Peña et al., 2007; Torres-Pacheco et al., 1996).

Several strategies have been addressed to control diseases caused by begomoviruses,. Some strategies are based on the avoidance of virus transmission through the control of whitefly vectors (Bemisia tabaci Genn.). However, the appearance of resistance of the vector to chemical insecticides is becoming a global problem. On the other hand, breeding for resistance presents the problem that sources for geminivirus resistance are scarce in most species (Ji et al., 2007; Lapidot and Friedmann, 2002; Shepherd et al., 2009; Vanderschuren et al., 2007).

Enhanced resistance to pathogens can be induced in plants by treatments with a variety of abiotic and biotic inducers (Walters and Heil, 2007). Abiotic inducers include nontoxic chemicals that can act at various points in the signaling pathways involved in disease resistance, providing longlasting, wide-spectrum resistance. Benzothiadiazole (BTH), a functional analogue of salicylic acid (SA), has been found to induce strongly defense reactions and the production of phenolic compounds. BTH was developed as an immunizing agent to sensitize various crops against pathogen infections. It has been also reported that BTH enhances the accumulation of soluble and cell wall-bound phenolic compounds in strawberry leaves, improving the resistance to powdery mildew infection (Hukkanen et al., 2007). The mode of action of BTH shares the property of activating the systemic acquired resistance (SAR) pathway downstream from the SA signaling (Delaney et al., 1994).

Salicylic acid (SA), a key signaling molecule for plant disease resistance, is synthesized by plants and induces accumulation of pathogenesis-related (PR) proteins to establish both local and systemic acquired resistance (SAR) against a diverse range of pathogens (Chen et al., 2010). The SA pathway has been reported to be activated by RNA viruses (Whitham et al., 2006). Equivalent information has only recently been reported for geminivirus infection. Ascencio-Ibañez et al. (2008) performed a global analysis of the Arabidopsis transcriptome upon infection with the geminivirus Cabbage leaf curl virus $(\mathrm{CaLCuV})$ and found that $\mathrm{CaLCuV}$ also triggers 
a pathogen response via the SA pathway. Furthermore, they showed that Arabidopsis cpr1 plants in which SA-mediated SAR is constitutively activated were less susceptible to $\mathrm{CaLCuV}$ infection, indicating that constitutive activation of the SA pathway impairs geminivirus infection (Ascencio-Ibanez et al., 2008; Bowling et al., 1994).

Similarly, it was reported that Arabidopsis plants in which the expression of several components of the SA pathway (including the upstream regulator ACD6) have been induced are less susceptible to Beet severe curly top geminivirus (BSCTV) (Chen et al., 2010).

In this study, resistance to PepGMV infection was induced in pepper plants (cv. Sonora Anaheim) by activating the SA pathway using BTH treatment. The resistance was characterized by evaluating symptom appearance, virus accumulation and viral movement. Our results showed that BTH could be an attractive alternative to induce geminivirus resistance in pepper plants without significant damage to fruit quality and productivity.

\section{MATERIAL AND METHODS}

Plant material and growth conditions

C. annuum cv. Sonora Anaheim plants were grown on 3:1:1 Mix3-Sunshine (SunGro, Bellevue,WA), vermiculite, and perlite (vol/vol/vol ratio) in a controlled environment at $25^{\circ} \mathrm{C}$ with a photoperiod of $16 \mathrm{~h}$ day / $8 \mathrm{~h}$ night.

BTH application and viral Inoculation

Benzothiadiazole or BTH (Actigard, Syngenta Crop Protection, Inc) applications were standardized using previously reported concentrations of $300 \mathrm{mg} / \mathrm{L}$ (Görlach et al., 1996; Hukkanen et al., 2007). Our standard treatment (1X) consisted of spraying plants once with the standard $300 \mathrm{mg} / \mathrm{L}$ solution. A $2 X$ or $3 X$ treatment consisted of spraying plants with the same solution (300mg/L) for 2 or 3 consecutive days. In some cases, plants received a " $0.5 \mathrm{X}$ " treatment that consisted of a similar single spray with a half-concentrated solution $(150 \mathrm{mg} / \mathrm{L})$. Most plants treatments were carried out on Sonora Anaheim plants at the 2-4 leaf stage.

After BTH application, plants were inoculated by biolistic delivery with a modified handheld low-pressure apparatus that allowed the targeting of a specific tissue (leaf). The fourth leaf (apical) on plants at the four-leaf stage (around 35 days post-germination) was directly inoculated at $120 \mathrm{psi}$ helium pressure with tungsten particles $(0.7 \mathrm{~mm}$, BioRad, Hercules, CA) covered with viral DNA (PepGMVAdimpBS + PepGMVBdimpBS) or with pBluescript for mock inoculations (Carrillo-Tripp et al., 2007). For symptom development experiments, a total of 20 plants were inoculated in several experiments.

Benzothiadiazole or BTH (Actigard, Syngenta Crop Protection, Inc) applications were standardized using previously reported concentrations of $300 \mathrm{mg} / \mathrm{L}$ (Görlach et al., 1996; Hukkanen et al., 2007). Our standard treatment (1X) consisted of plants being sprayed once with the standard $300 \mathrm{mg} / \mathrm{L}$ solution. A $2 \mathrm{X}$ or $3 \mathrm{X}$ treatment consisted of plants being sprayed with the same solution $(300 \mathrm{mg} / \mathrm{L})$ for 2 or 3 consecutive days. In some cases, plants received a " $0.5 \mathrm{X}$ " treatment that consisted of a similar single spray with a half- concentrated solution $(150 \mathrm{mg} / \mathrm{L})$. Most plants treatments were carried out at the 2-4 leaf stage.

After BTH application, plants were inoculated with PepGMV at different intervals using a biolistic delivery device (handheld low-pressure apparatus). One individual leaf from each plant was directly inoculated at 120 psi helium pressure with tungsten M-10 particles (0.7 Micron, BioRad) covered with $200 \mathrm{ng}$ of each viral DNA component (PepGMV A, PepGMV B) as previously reported (Carrillo-Tripp et al., 2007). As control, some plants were mock-inoculated with pBluescript DNA. For symptom development experiments, a total of 20 plants were inoculated in several experiments.

\section{DNA Isolation and PCR}

Total DNA was isolated by grinding young, systemic tissue with liquid nitrogen in the presence of CTAB buffer (Murray and Thompson, 1980). The relative level of PepGMV DNA was evaluated by quantitative PCR as previously reported (Carrillo-Tripp et al., 2007). The primers used in this study are as follows: for Rep gene (encoding replication-associated protein), PepGMVRepq5' ( $5^{\prime}$ - C A A A GCTGGTGA T C CGAAA A C G - 3' ) and PepGMVRepq3' (5'-GTTAAACGAGGATAATGGATAAGG-3'), expected PCR product of121 bp. The housekeeping primers were $\beta$-tubulin forward (5'-TCCAGTGTTCTGTGACATCCCGCCTAG- ${ }^{\prime}$ ) and $\beta$-tubulin reverse (5'-CTCCATTTCGTCCATTCCTTCACCTGTG-3').

\section{RNA Isolation and Real-time PCR}

Total RNA was isolated by grinding leaf tissue in liquid nitrogen in the presence of TRIzol reagent (Invitrogen Life Technologies). Possible DNA contamination was evaluated by PCR. One mg of total RNA was used to generate cDNA with Superscript II reverse transcriptase (Life technologies) using oligo(dT) ${ }_{18}$. Real-time PCR for relative quantification was performed in 20- $\mu$ l reactions using 12.5 ng of cDNA, Platinum SYBR Green qPCR Super Mix UDG (Life technologies) in a BioRad iCycler thermocycler. A melting curve was programmed after each run

to verify the lack of primer dimerization and nonspecific amplification. Maximal amplification efficiency was assumed for all samples at a determined threshold in log phase with the following formula: $\mathrm{T}=\mathrm{X} 2 \mathrm{CT}$, where $\mathrm{T}$ was the selected threshold of fluorescence units, $\mathrm{X}$ was the initial copy number, and CT was the cycle number crossing the threshold. Relative units were calculated against the sample with the highest concentration. The following PCR primers were used in this study: $\beta$-tubulin forward (5'-TCCAGTGTTCTGTGACATCCCGCCTAG-3'), $\beta$-tubulin reverse (5'-CTCCATTTCGTCCATTCCTTCACCTGTG-3'); PR-1 forward (5'-CCCAAAATTACGCCAATCAAAG-3'), PR-1 reverse (5'-ACATCTTCACGGCACCAG-3').

\section{Southern blot analysis}

Systemic leaf tissue from five infected plants was collected. Total DNA was extracted as described earlier (Méndez-Lozano et al., 2003). Two micrograms of total DNA were loaded into a $1 \%$ agarose gel. After electrophoresis, DNA was transferred to Hybond N+ membrane (Amersham Biosciences, Piscataway, 
NJ) by capillary action with a solution of $10 \mathrm{X}$ sodium citrate (SSC) and crosslinked by UV irradiation. PepGMV A DNA used as probe was radioactively labeled using Redi prime II Kit and (a-32P) dCTP (Amersham). Hybridization was performed overnight at $50{ }^{\circ} \mathrm{C}$ as described (Hutvágner et al., 2000). After hybridization, membranes were washed twice with a 2 X SSC, $1 \%$ sodium dodecyl sulfate (SDS) solution and twice with $0.5 \mathrm{X}$ SSC, $1 \%$ SDS. All washes were carried out at $50{ }^{\circ} \mathrm{C}$. Hybridization signals were detected on a phosphorimager system.

Viral movement evaluation

Pepper plants previously sprayed with BTH were infected with PepGMV. To analyze virus movement, inoculated leaves were detached 48 hours after inoculation (hpi) as previously described (García-Neria and Rivera-Bustamante, 2011). Symptom appearance was then evaluated daily and up to $9 \mathrm{dpi}$.

It was previously reported that in susceptible pepper plants, PepGMV will reach the vascular tissue and move out of the inoculated leaf in less than $48 \mathrm{hr}$, and therefore be able to cause symptoms. In resistant plants, where the virus movement is affected, the virus will not be able to move out of the inoculated leaf, thus the detachment of that leaf will prevent the establishment of the infection.

Viral movement was also evaluated in systemically infected leaves using a modified PepGMV-A component. The complete coat protein $(\mathrm{CP})$ gene of PepGMV component A was replaced by the GFP gene, in such a way that the transcription of GFP was controlled by the viral CP promoter as described (Méndez-Lozano et al., 2003). Fluorescence was monitored using a Leica DMRE microscope. Images were generated by a digital camera (Spot Diagnostic Instruments) and edited with Adobe Photoshop CS software.

Productivity assay

C. annuum cv. Sonora Anaheim and Serrano Tampiqueño 74 plants were grown on 3:1:1 Mix3-Sunshine (SunGro, Bellevue,WA), vermiculite and perlite $(\mathrm{v} / \mathrm{v} / \mathrm{v})$ in a controlled environment at $25^{\circ} \mathrm{C}$ with a photoperiod of $16 \mathrm{~h}$ day/8h night. Ten plants of each cultivar at the four-leaf stage were sprayed on the leaves with BTH solution $(300 \mathrm{mg} / \mathrm{L})$ on 3 consecutive days. As controls 10 plants of each cultivar were sprayed only with water or not sprayed (N/A). Plants were observed daily until fruit production. The ripe fruits were harvested and evaluated at 45, 75 y 120 days post-BTH application.

\section{RESULTS}

Resistance analysis

Most plants respond to virus infections by triggering defense responses such as systemic acquired resistance (SAR). However, it is believed that in most cases the response is too slow to prevent the establishment of the infective cycle. Therefore, strategies designed to induce an earlier SAR response (even before virus infection) include the use of SA analogues. Most studies, however, focus on RNA viruses and little information is available for ssDNA geminiviruses.

To verify the effect of BTH on PepGMV infection, pepper plants at the stage of 2-4 leaves were first sprayed with BTH for three consecutive days (3X treatment) using a 300
mg/L solution. BTH-treated plants were then inoculated with PepGMV and monitored for symptom expression. It has been previously reported that under the conditions used here for plant inoculation and incubation, typically $100 \%$ of the inoculated plants have already developed symptoms by day 9 (9 dpi) (Góngora-Castillo et al., 2012). In the case of the BTH-treated plants, only $30 \%$ of the inoculated plants developed the typical symptoms. On the other hand, all control (untreated) plants presented the typical symptoms (Figure 1B). Quantification of viral DNA of symptomatic and non-symptomatic plants revealed that the $30 \%$ of the BTHtreated, inoculated plants that developed typical symptoms presented similar viral DNA concentration to that found in untreated infected plants, suggesting that in these cases BTH treatment failed to induced a SAR defense response. Overall, this result suggests that indeed BTH treatment could generally prevent PepGMV infection. Notably, an atypical phenotype that consisted of smaller-sized plants and mild crumpling of the leaves was generally observed in BTH-treated plants, even in those not inoculated with PepGMV (Figure 1A).

In order to characterize the mild phenotype caused by BTH treatment and evaluate the protection efficiency we carried out some dose-effect experiments using several variations of the $\mathrm{BTH}$ treatment (concentration and number of applications). Basically, plants were sprayed once with BTH concentrations of 150 or $300 \mathrm{mg} / \mathrm{Lt}$ (considered as $0.5 \mathrm{X}$ and $1 \mathrm{X}$, respectively), or 2-3 times with the standard concentration of $300 \mathrm{mg} / \mathrm{Lt}$ ( $2 X$ and $3 X$ treatments). Two important observations were obtained here. First, an inverse correlation between the overall symptomology (percentage of symptomatic plants and the severity of symptoms) was observed with higher dose treatments (Figure 2A). PepGMV symptoms were less evident in plants treated with higher BTH dose (2X or $3 \mathrm{X})$. In addition, and probably more importantly, the percentage of symptomatic plants was dramatically reduced at higher BTH dose. Figure 2B shows that only $30 \%$ of the plants inoculated with PepGMV 5 days after 3X BTH treatment (5 dpa) developed symptoms, while all control plants were symptomatic 9 days after inoculation (dpi). Even $2 X$ and $1 X$ treatments showed important reduction in the percentage of symptomatic plants (40 and $70 \%$, respectively).

Considering the possible field application of BTH treatments, we were interested in knowing how long BTH will protect against PepGMV infection. Therefore we also carried out virus inoculation experiments in which PepGMV was inoculated at different times after BTH treatment. Figure $2 \mathrm{~B}$ shows that the protection obtained with BTH treatment was less evident when the plants were inoculated 10 or 15 days after the BTH treatment (10, 15 dpa). For example, when plants were inoculated with PepGMV 5 days after BTH application, only $40 \%(2 \mathrm{X})$ and $30 \%(3 \mathrm{X})$ of the plants became symptomatic, whereas similar treatments carried out at 15 dpa resulted in $80 \%$ and $50 \%$ of symptomatic plants. In other words, the effectiveness of BTH protection decreases over time. Nevertheless, the effect of BTH treatment might be still important after 15 days, especially after a high initial dose such as the ones used in $2 \mathrm{X}$ or $3 \mathrm{X}$ treatments.

The second observation was related to the phenotype obtained with BTH application. The observed phenotype showed a dose-dependent gradient, since at lower doses of BTH the leaf-crumpling and slow-growing phenotype was not observed (Figure 2A). 

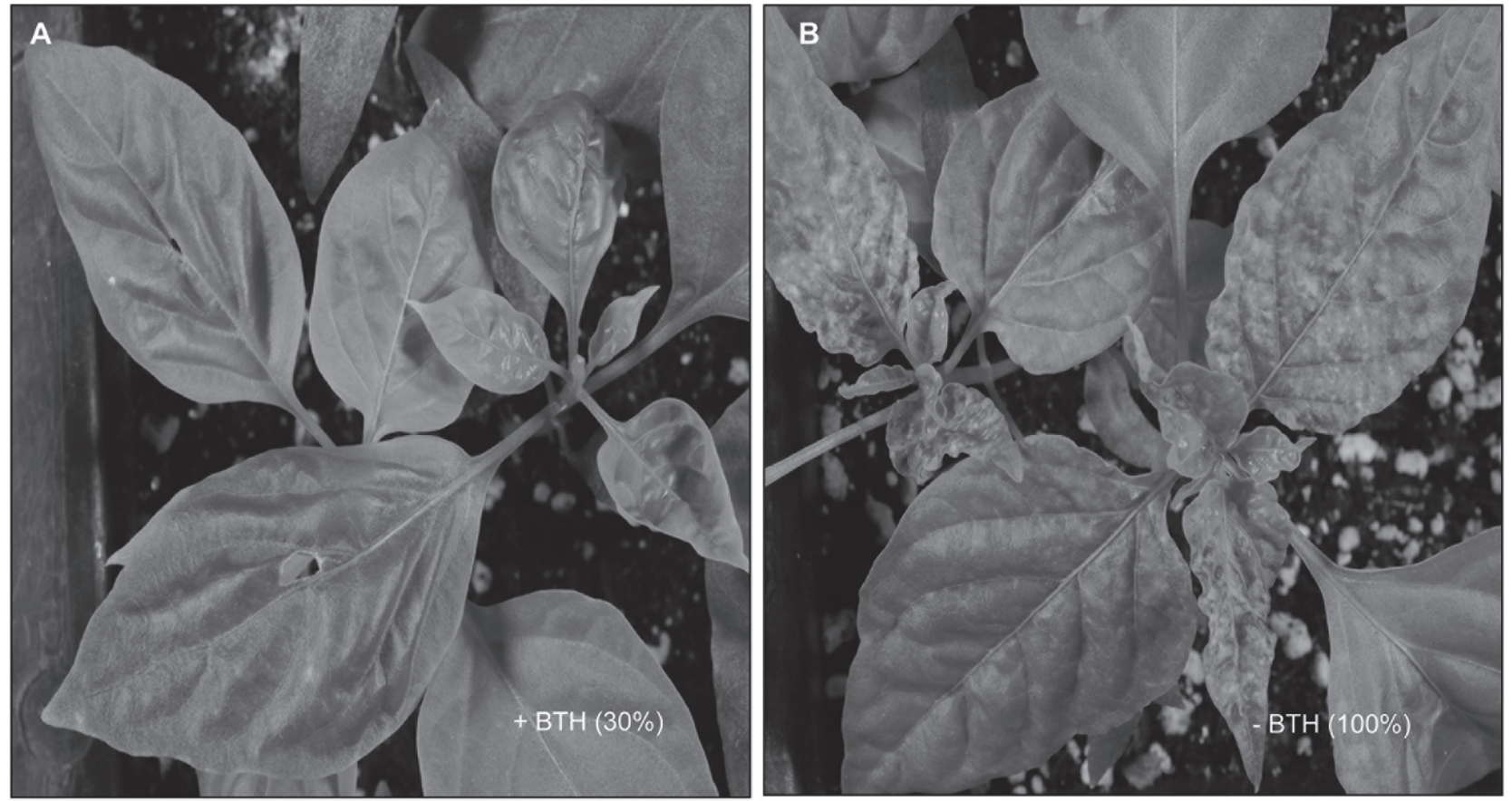

Figure 1: Phenotypes observed in infected plants at 9 dpi. (A) Pepper plant treated with BTH and inoculated with PepGMV. A mild atypical phenotype is observed. (B) Plants inoculated with PepGMV (no BTH treatment) showing rugosity and yellow mosaic symptoms typical of a PepGMV infection.

A

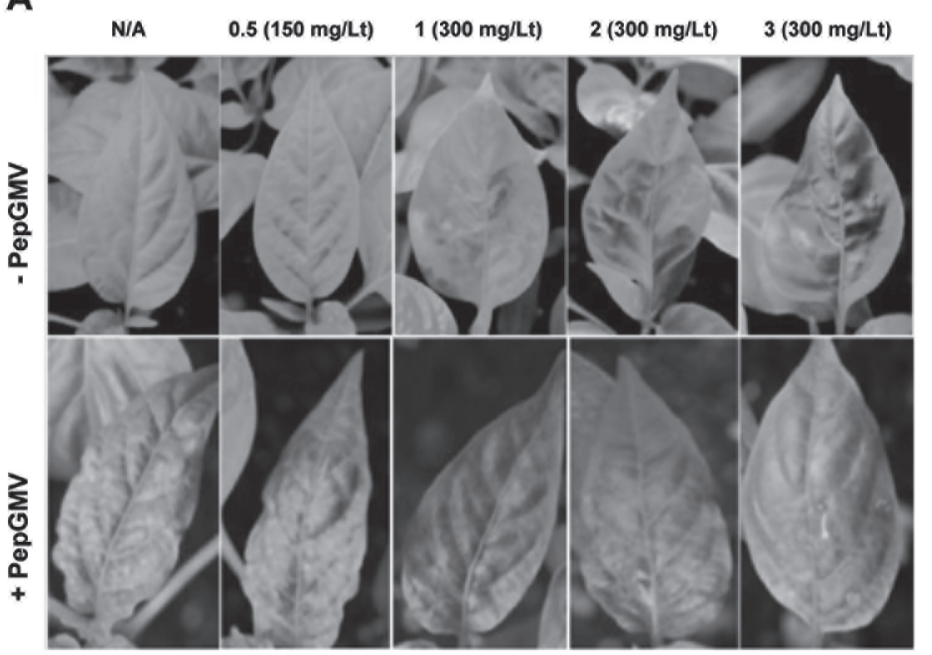

B

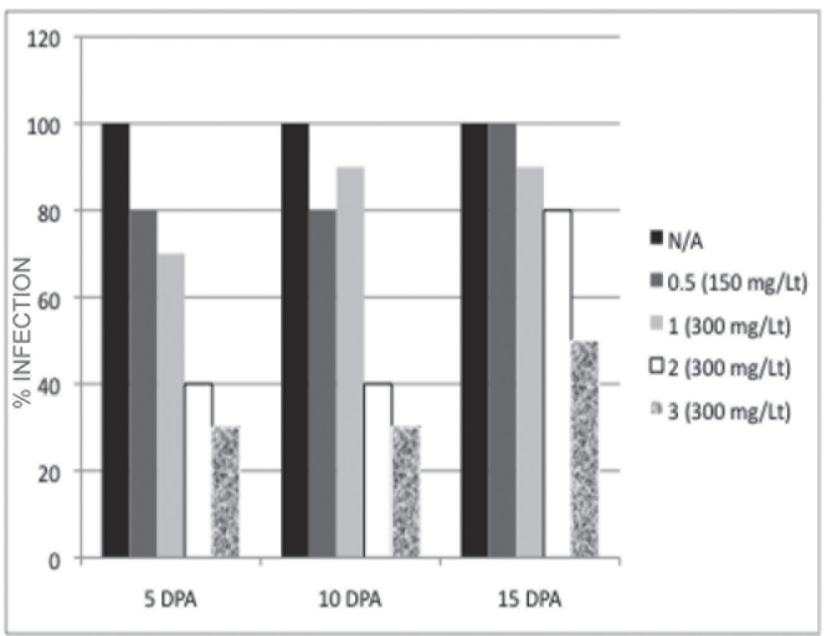

Figure 2: Effect of BTH on pepper plants. (A) Pepper plants treated with different concentrations of BTH show a dose-dependent response. The severity of the atypical symptoms was greater in plants treated with higher dose of BTH. N/A, no BTH application; 0.5, treatment with half the standard $300 \mathrm{mh} / \mathrm{L}$ concentration; 1, 2 and 3, days of consecutive treatments with standard BTH concentration. (B) Symptoms observed in pepper plants treated with BTH and inoculated with PepGMV. An increasing reduction of PepGMV symptoms is observed at higher BTH doses.

Marker of SAR is induced in BTH plants.

As an SA analogue, BTH has the property of activating the systemic acquired resistance (SAR) pathway (Delaney et al., 1994). In order to verify that the SA pathway was turned on in pepper plants treated with BTH we analyzed the expression of a pathogenesis-related protein gene, $P R-1$. $P R-1$ expression has been considered as a hallmark for the SA pathway, therefore, a quantitative PCR procedure was used to analyze the effect of BTH on PR-1 expression. Figure 3 shows that indeed BTH treatment induces the expression of $P R-1$. The highest $P R-1$ expression was observed around 6 days after BTH application 
(6 dpa). This result suggests that the resistance to geminivirus infection observed in BTH-treated plants might be due at least partially to a SAR response. The fact that $P R-1$ transcript level sharply decreased over time correlates with a single dose type of response rather than the extended, wide response observed in the case of pathogen infections (Garcia-Neria and RiveraBustamante, 2011).

\section{Evaluation of PepGMV accumulation in systemically infected tissue}

Several techniques have been explored to evaluate viral replication. These include agroinoculation of leaf discs (Czosnek et al., 1993; Day et al., 1991), transformation of protoplasts from candidate plants (Brunetti et al., 2001; Lucioli et al., 2003) and cell suspension cultures (LopezOchoa et al., 2006; Méndez-Lozano et al., 2003). In this study, virus replication was evaluated in inoculated and systemic leaf tissue from BTH-treated plants using Southern blot hybridization assays and a quantitative PCR procedure to detect viral DNA. The assay was carried out inoculating PepGMV using a handheld biolistic gun that allows a localized, direct inoculation into a single leaf (Carrillo-Tripp et al., 2007). Both inoculated and systemic leaves were collected at 5 and 9 dpi. At $5 \mathrm{dpi}$, the concentration of viral DNA (as a measure of virus replication) was similar in BTH-treated and control plants in the two types of tissues (inoculated and systemic leaves). However, at 9 dpi a dramatic difference in viral DNA concentration was observed, especially in the comparison of systemic leaves in control plants to BTHtreated samples (Figure 4; $9 \mathrm{dpi}, \mathrm{S}$ tissues). A similar result was observed in Southern blot analysis (Figure 4B). The levels of PepGMV replication in untreated systemic tissue were similar to those reported earlier (Renteria-Canett et al., 2011). However, in the equivalent tissue from BTH-treated plants the concentration of viral DNA showed a 5-6 fold decrease. These results suggest that virus replication is affected in BTH treated plants. However, a concomitant alteration of virus movement cannot be excluded, since that situation might result in a lower number of infected cells, and therefore a reduction of total viral DNA (Renteria-Canett et al., 2011).

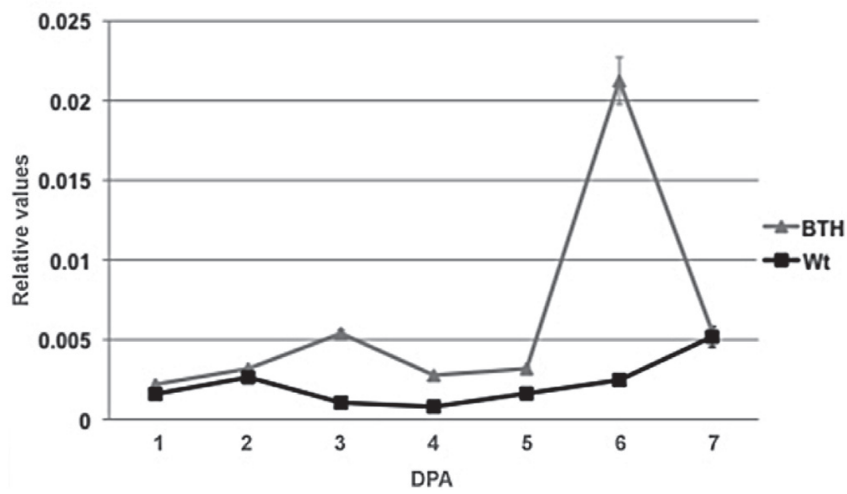

Figure 3: Induction of PR-1 gene expression by BTH treatment. The expression of PR-1 gene in BTH treated plants was evaluated using a quantitative PCR assay. Leaf samples were collected daily after BTH treatment and compared to the untreated control. The expression of $\beta$-tubulin gene was use to normalized the assay. $\mathrm{DPA}=$ days after $\mathrm{BTH}$ application
Evaluation of PepGMV movement in BTH plants.

To analyze if virus movement was affected in BTH-treated plants, we designed two types of experiments based on the use of a fluorescence-expressing virus construct and the timely detachment of the inoculated leaf.

Virus movement in systemically infected leaves was previously studied using a PepGMVA-GFP chimeric construction (Méndez-Lozano et al., 2003). Plants are inoculated with PepGMV-GFP construction and both inoculated and systemic leaf tissues are observed under UV light irradiation in a stereoscope or under a fluorescence microscope. Typical results are shown in Figure 5A. Untreated plants (N/A) showed good GFP expression in both inoculated and systemic tissue observed at 5 and $10 \mathrm{dpi}$. Since the virus coat protein was replaced with the GFP gene, individual infected cells can be identified by the green fluorescence. BTH treatment did not affect the GFP transcript level in the inoculated leaf tissue. A similar transcript level of GFP was observed in all treatments. However, 2-day application $(2 X)$ of BTH resulted in a reduction of virus movement into the systemic leaves and no infected (fluorescent) cells were detected at 10 days. In the case of the strongest BTH treatment

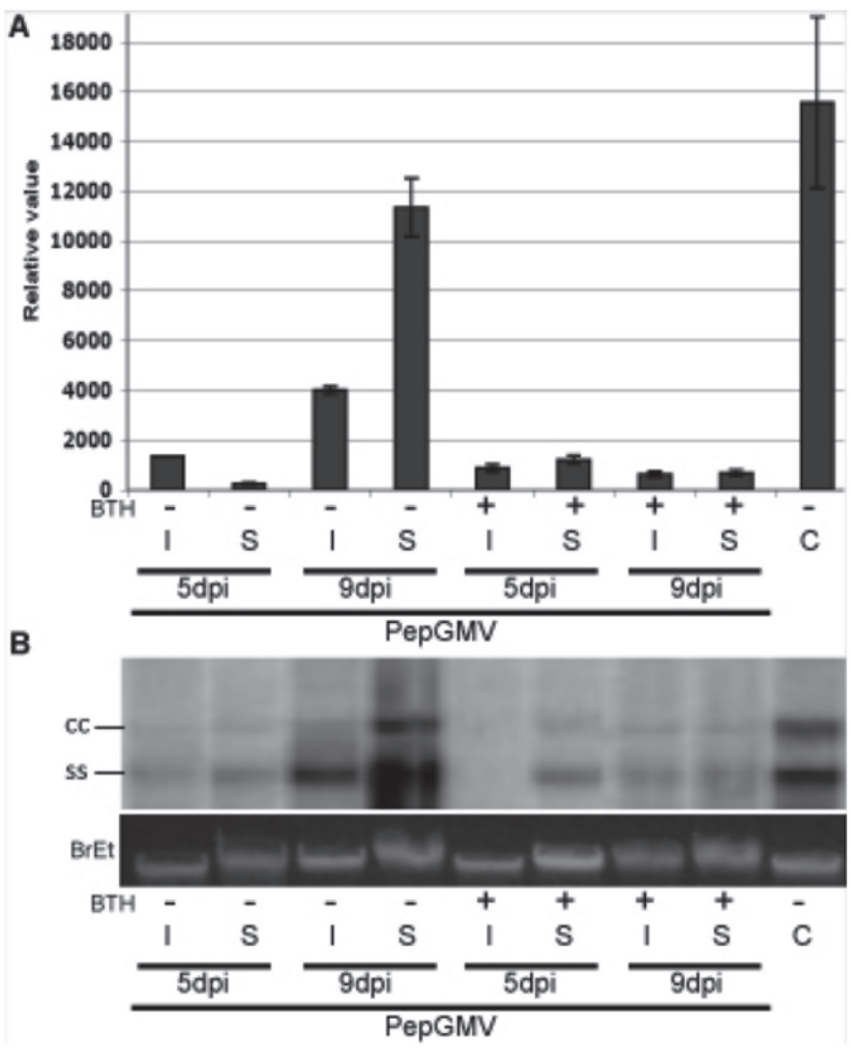

Figure 4: Quantification of PepGMV DNA and efficiency of BTH treatment over time. (A). Leaf tissue was collected from BTH-treated and control pepper plants several days after inoculation (dpi). The two types of tissues were analyzed: inoculated leaf (I) and systemic, non-inoculated tissue (S). Viral DNA quantification was performed using a Real-time PCR procedure. Standard deviation is shown in each case. (B) To verify the presence of all molecular intermediates in viral replication, DNA samples from each stage were analyzed by Southern blot using PepGMV DNA as probe. 
(3X, 3-day application), no infected cells were detected in tissues collected at $5 \mathrm{dpi}$ or $10 \mathrm{dpi}$.

\section{A} PepGMV A-GFP + PepGMV B
Inoculated tissue
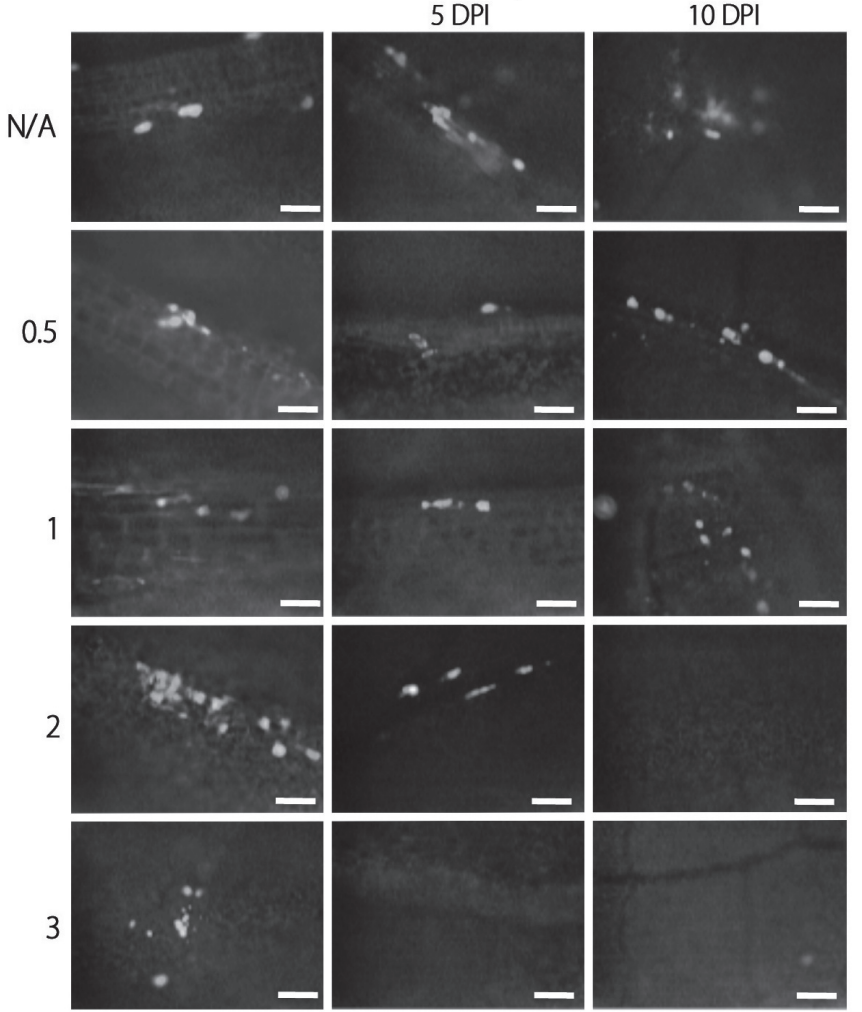

B

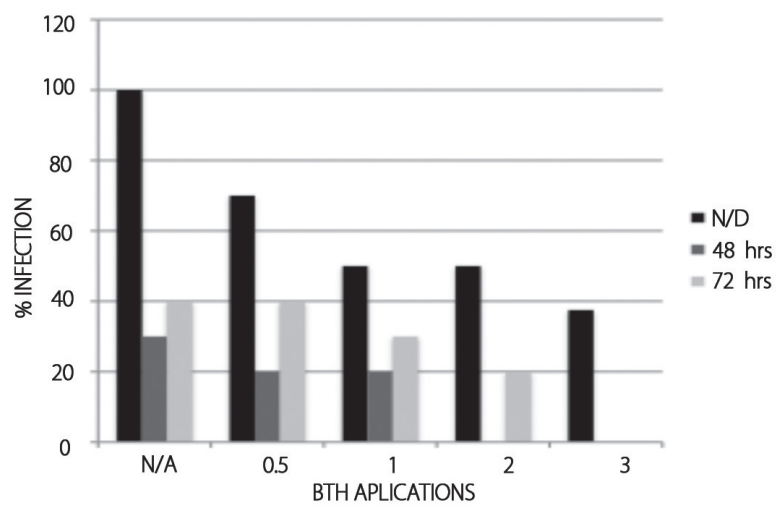

Figure 5: Evaluation of PepGMV movement in BTH-treated plants. (A) Sonora Anaheim pepper plants treated with BTH were inoculated with a PepGMV-GFP construction (see Figure 2 for BTH treatments). Both inoculated and systemic tissues were observed using a fluorescence microscope to detect GFP. In the latter case, observations were performed at 5 and $10 \mathrm{DPI}$. The number of fluorescent, infected cells was reduced at higher BTH doses. (B) Inoculated leaf detachment experiments. The Inoculated leaf was detached from the plants at several time points after inoculation. If virus movement is efficient and can move out of the inoculated leaf, symptoms will develop. Control plants (no detachment) show the expected reduction of percentage of infected plants with higher concentration of BTH. Almost all 2X-3X BTH-treated plants with inoculated leaves detached did not develop symptoms, suggesting that BTH affects PepGMV movement from the inoculated leaf into the rest of the plant
It has been previously reported that $48 \mathrm{~h}$ is sufficient for PepGMV to move inoculated plant. Detachment of the inoculated leaf 12, 24 or 36 hours after inoculation resulted in a dramatic reduction of the number of symptomatic plants (Garcia-Neria and Rivera-Bustamante, 2011). To verify the efficiency of virus movement in BTH-treated plants, PepGMV was inoculated in both BTH-treated and control plants, and the inoculated leaves were detached 48 or 72 hpi. Plants were then observed daily for symptom appearance. The results are summarized in Figure 5B. The percentage of infection was reduced as mentioned before in non-detached plants, however in plants detached at 48 and $72 \mathrm{hrs}$. an evident reduction was observed. These results suggest that virus movement was indeed altered in plants sprayed with BTH.

Productivity of BTH-treated plants is not affected.

The atypical phenotype observed in BTH-treated plants, especially when evaluated a few days after application, raised some concern about the feasibility of using BTH for

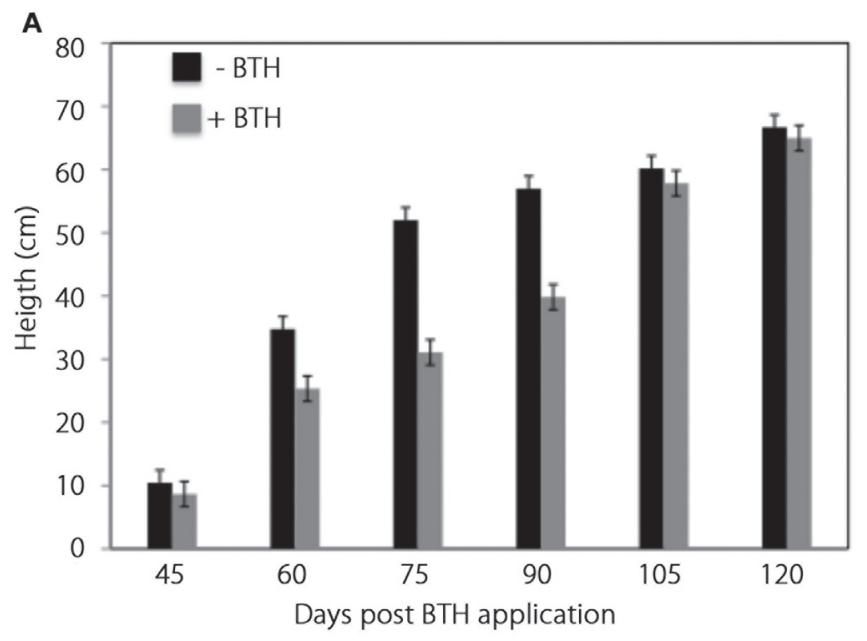

B

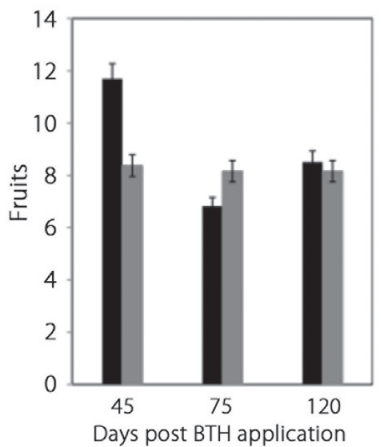

C

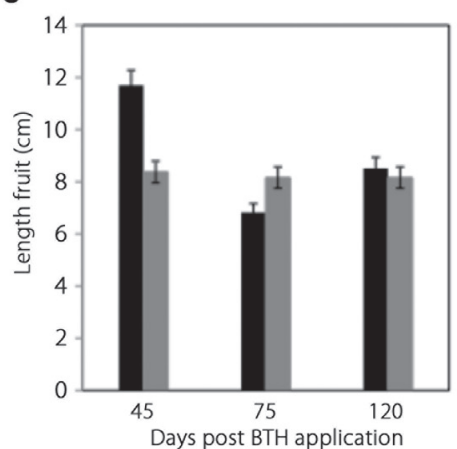

Figure 6: Effect of BTH on pepper productivity. (A) The height of BTH-treated and control pepper plants was evaluated up to 120 days after application (3X treatment). Untreated plants initially reached a higher size, however around $100 \mathrm{dpa}$ the size of both groups was practically the same. (B and C) The effect on productivity was evaluated by comparing the number and size of pepper fruits from both groups of plants. Groups of 10 plants each were used in these experiments and two pepper cultivars, Sonora Anaheim and Serrano Tampiqueño 74, were used in independent repetitions. 
commercial purposes. Therefore, we carried out experiments to compare the productivity of BTH-treated plants with the equivalent untreated controls. Several parameters were verified. The first parameter evaluated was the size of the plant, since it was one of the first obvious differences noticed a few days after BTH treatment (Figure 6A). Other parameters were related to pepper productivity; the number and size of the pepper fruits (Figure 6B and $\mathrm{C}$ ) and quality; pungency and vitamin $C$ content. Twenty pepper plants were grown in large containers, required for long-term studies. Half of the population was treated with BTH and then evaluated every week in terms of plant size, number of flowers and number and size of fruits. Vitamin $C$ and pungency were evaluated in fruits collected at 45, 75 and 120 days. The experiments were carried out with two varieties (Sonora Anaheim and Serrano Tampiqueño 74) to discount variety-specific effects.

The results showed that after the initial differences observed between control and BTH-treated plants, the latter "recovered" in most parameters evaluated, especially when evaluated after 50-75 days. Figure 6 shows that in the case of plant height, untreated plants showed a larger size compared to BTH-treated ones. However, at age 100 days both types of plants were practically equal in size. On the other hand, fruit number and size were practically the same after 50-60 days. Pungency and Vitamin C content did not show significant differences between the fruits obtained from BTH treated and untreated control plants. The results shown here were obtained with the Sonora Anaheim cultivar, however similar results were also observed with Serrano the Tampiqueño 74 cultivar. The fact that an important variability was observed between samples collected from plants from the same lot (treated or untreated) complicated the analysis (data not shown).

\section{DISCUSSION}

Many compounds have been commercially released in some countries as plant health promoters for annual crops (Chen and Li, 2006). Benzo (1,2,3)-thiadiazole-7-carbothioic acid-Smethyl ester, or BTH, was developed as a potent SAR activator that possess not only antimicrobial properties, but also increases crop resistance to diseases by activating SAR signal transduction pathways in several plant species (Thakur and Sohal, 2013).

In the case of plant viral diseases, most studies with SA analogues have centered on RNA viruses. For example, the effect of BTH was studied on tobacco plants infected with TMV. BTH pre-treatment caused an important reduction in the multiplication of TMV in the locally-infected leaves, while a 4-day delay was observed in the multiplication of TMV in systemically infected leaves. Another example is the inverse correlation reported in tobacco between the number of local lesions caused by Tomato spotted wilt virus (TSWV) and the application of acibenzolar-S-methyl (ASM), another SA analogue (Mandal et al., 2008). In both cases, changes in the expression of genes involved in defense pathways (e.g., PR proteins, ribonucleases and phosphodiesterase, PDE) were also described. Wide pathogen resistance has also been reported for these chemicals. BTH-treated Arabidopsis thaliana plants were described as resistant to infection by turnip crinkle virus, Pseudomonas syringae pv 'tomato' DC3000 and Peronospora parasitica (Lawton et al., 1996).
Little information is available on the effect of BTH on geminivirus infected plants. However, some reports suggest that BTH treatment might have some effect on plant resistance to the $\mathrm{B}$ and $\mathrm{Q}$ biotypes of Bemisa tabaci (Gennadius), the vector for begomoviruses (Nombela et al., 2005). In this study, we report the effect of BTH treatment of pepper plants with regard to the infection with an economically-important, widely distributed begomovirus, PepGMV.

Treatment of pepper plants with BTH reduced the percentage of infected plants and the plants that became infected displayed less severe symptoms. The reduction was directly correlated with the concentration of BTH and the time period between BTH application and the inoculation with the virus. In addition, to confirm the induction of SAR pathway (PR-1 expression), the resistance shown by BTH plants was evaluated in terms of virus replication and movement. It is complicated to separate these activities for evaluation in a whole plant. Replication can be evaluated at the protoplast level, but these results are difficult to extrapolate to the entire plants, especially in the case of chemically induced resistance. The harsh procedure to isolate protoplasts might have an impact on the replication assay. The results reported here demonstrate that the virus infective cycle is affected in BTH treated plants, although it is not completely clear if the effect can be restricted to a single process (e.g. replication or movement). Due to the high coordination between virus replication and movement, it is likely that both functions are affected in the plant.

PepGMV has been reported to be restricted to the vascular tissue. Those results were obtained using in situ hybridization (Renteria-Canett et al., 2011). The results reported here with PepGMV-GFP fusions show a similar tissue localization. An advantage of this technique is that it is a non-destructive procedure and plants can be monitored at several time points without disturbing them by tissue sampling (e.g., wounding plants by cutting leaves). Another important observation is that BTH treatment does not affect the normal localization of the virus (e.g., PepGMV did not invade different tissues), therefore the effect could be explained mainly as an overall reduction of the number of infected cells.

The initial experiments with a high concentration of BTH induced an atypical phenotype of the treated plants. In those experiments the plants were evaluated for only a few days and a main concern was that BTH, although beneficial to inhibit virus infection, could also affect crop productivity. This negative effect could therefore restrict the application of BTH at the commercial level. Analyzing the BTH treated plants for longer periods, up to 120-150 days after BTH application, demonstrated that the plants were able to recover from the initial phenotype and their productivity was practically the same as that obtained with untreated pepper plants. The number and size of the fruits obtained was practically equal for treated and untreated plants in the last two time points analyzed. Similarly, 120 days after treatment the size of the two types of plants was not statistically different.

These experiments carried out in greenhouses (mainly because some plants were infected with PepGMV) will have to be repeated directly under field conditions and varied environmental parameters. However, it is very likely that similar results are to be expected. Finally, economic analysis remains to be performed to verify the feasibility of BTH treatments at larger scales. 


\section{ACKNOWLEDGEMENTS}

DLTS and MAGN acknowledge fellowship support from Conacyt Mexico. This research was also supported by a Conacyt Research Grant to RFRB.

\section{REFERENCES}

(SIAP-SAGARPA) SDIAYP (2012) Producción Agrícola en México. (Servicio de Infomación Agroalimentaria y Pesquera (SIAP) - Secretaría de Agricultura, Ganadería, Desarrollo Rural, Pesca y Alimentación (SAGARPA)). pp Servicio de Infomación Agroalimentaria y Pesquera (SIAP) - Secretaría de Agricultura, Ganadería, Desarrollo Rural, Pesca y Alimentación (SAGARPA).

ASCENCIO-IBANEZ JT, SOZZANI R, LEE TJ, CHU TM, WOLFINGER RD, CELLA R, HANLEY-BOWDOIN L (2008) Global analysis of Arabidopsis gene expression uncovers a complex array of changes impacting pathogen response and cell cycle during geminivirus infection. Plant Physiology 148: 436-454.

BOWLING SA, GUO A, CAO H, GORDON AS, KLESSIG DF, DONG XI (1994) A MUTATION IN ARABIDOPSIS THAT LEADS TO CONSTITUTIVE EXPRESSION OF SYSTEMIC ACQUIREDRESISTANCE. Plant Cell 6: 1845-1857.

BRUNETTI A, TAVAZZA R, NORIS E, LUCIOLI A, ACCOTTO GP, TAVAZZA M (2001) Transgenically expressed T-Rep of Tomato yellow leaf curl Sardinia virus acts as a trans-dominant-negative mutant, inhibiting viral transcription and replication. Journal of Virology 75: 10573-10581.

CARRILLO-TRIPP J, LOZOYA-GLORIA E, RIVERA-BUSTAMANTE RF (2007) Symptom remission and specific resistance of pepper plants after infection by Pepper golden mosaic virus. Phytopathology 97: 51-57.

CHEN H, ZHANG Z, TENG K, LAI J, ZHANG Y, HUANG Y, LI Y, LIANG L, WANG Y, CHU C and others (2010) Up-regulation of LSB1/GDU3 affects geminivirus infection by activating the salicylic acid pathway. Plant Journal 62: 12-23.

CHEN P, LI Z (2006) BTH systemic induction to defense related enzymes in wheat leaves. Acta Botanica Boreali-Occidentalia Sinica 26: 2468-2472.

CZOSNEK H, KHEYR-POUR A, GRONENBORN B, REMETZ E, ZEIDAN M, ALTMAN A, RABINOWITCH HD, VIDAVSKY S, KEDAR N, GAFNI Y and others (1993) Replication of Tomato yellow leaf curl virus (TYLCV) DNA in agroinoculated leaf discs from selected tomato genotypes. Plant Molecular Biology 22: 995-1005.

DAY AG, BEJARANO ER, BUCK KW, BURRELL M, LICHTENSTEIN CP (1991) Expression of an antisense viral gene in transgenic tobacco confers resistance to the DNA virus Tomato golden mosaic virus. Proceedings of the National Academy of Sciences of the United States of America 88: 6721-6725.

DELANEY TP, UKNES S, VERNOOIJ B, FRIEDRICH L, WEYMANN K, NEGROTTO D, GAFFNEY T, GUTRELLA M, KESSMANN H, WARD $\mathrm{E}$ and others (1994) A central role of salicylic-acid in plant-disease resistance. Science 266: 1247-1250.

FAUQUET CM, BRIDDON RW, BROWN JK, MORIONES E, STANLEY J, ZERBINI M, ZHOU X (2008) Geminivirus strain demarcation and nomenclature. Archives of Virology 153: 783-821.

FAUQUET CM, STANLEY J (2005) Revising the way we conceive and name viruses below the species level: A review of geminivirus taxonomy calls for new standardized isolate descriptors. Archives of Virology 150: 2151-2179.

GARCIA-NERIA MA, RIVERA-BUSTAMANTE RF (2011) Characterization of Geminivirus Resistance in an Accession of Capsicum chinense Jacq. Molecular Plant-Microbe Interactions 24: 172-182.

GÓNGORA-CASTILLO E, IBARRA-LACLETTE E, TREJO SAAVEDRA D, RIVERA-BUSTAMANTE R (2012) Transcriptome analysis of symptomatic and recovered leaves of geminivirus-infected pepper (Capsicum annuum). Virology Journal 9: 295.

GÖRLACH J, VOLRATH S, KNAUF-BEITER G, HENGY G, BECKHOVE U, KOGEL K-H, OOSTENDORP M, STAUB T, WARD E, KESSMANN $\mathrm{H}$ and others (1996) Benzothiadiazole, a novel class of inducers of systemic acquired resistance, activates gene expression and disease resistance in wheat. The Plant Cell 8: 629-643.

HOLGUÍN-PEÑA RJ, RIVERA-BUSTAMANTE RF, CARRILLO-TRIPP J (2007) Pepper golden mosaic virus and related geminiviruses affecting tomato crops. G P Rao, Kumar P L, Holguin-Peña. R J, eds In: Characterizacion, Diagnosis \& Management of Plant Viruses. Vol. 3: Vegetable and Pulse Crops. (Studium Press LLC). pp 163-193.
HUKKANEN AT, KOKKO HI, BUCHALA AJ, MCDOUGALL GJ, STEWART D, KARENLAMPI SO, KARJALAINEN RO (2007) Benzothiadiazole induces the accumulation of phenolics and improves resistance to powdery mildew in strawberries. Journal of Agricultural and Food Chemistry 55: 1862-1870.

HUTVÁGNER G, MLYNÁROVÁ L, NAP JP (2000) Detailed characterization of the posttranscriptional gene-silencing-related small RNA in a GUS gene-silenced tobacco. RNA 6: 1445-54.

JI Y, SCOTT J, HANSON P, GRAHAM E, MAXWELL D (2007) Sources of resistance, inheritance, and location of genetic loci conferring resistance to members of the tomato-infecting begomoviruses. In: Tomato Yellow Leaf Curl Virus Disease. pp 343-362.

LAPIDOT M, FRIEDMANN M (2002) Breeding for resistance to whiteflytransmitted geminiviruses. Annals of Applied Biology 140: 109-127.

LAWTON KA, FRIEDRICH L, HUNT M, WEYMANN K, DELANEY T, KESSMANN H, STAUB T, RYALS J (1996) Benzothiadiazole induces disease resistance in Arabidopsis by activation of the systemic acquired resistance signal transduction pathway. The Plant Journal 10: 71-82.

LÓPEZ-OCHOA L, RAMÍREZ-PRADO J, HANLEY-BOWDOIN L (2006) Peptide aptamers that bind to a geminivirus replication protein interfere with viral replication in plant cells. J Virol 80: 5841-53.

LUCIOLI A, NORIS E, BRUNETTI A, TAVAZZA R, RUZZA V, CASTILLO AG, BEJARANO ER, ACCOTTO GP, TAVAZZA M (2003) Tomato yellow leaf curl Sardinia virus Rep-derived resistance to homologous and heterologous geminiviruses occurs by different mechanisms and is overcome if virus-mediated transgene silencing is activated. Journal of Virology 77: 6785-6798.

MANDAL B, MANDAL S, CSINOS AS, MARTÍNEZ N, CULBREATH AK, PAPPU HR (2008) Biological and molecular analyses of the acibenzolarS-methyl-induced systemic acquired resistance in flue-cured tobacco against Tomato spotted wilt virus. Phytopathology 98: 196-204.

MÉNDEZ-LOZANO J, TORRES-PACHECO I, FAUQUET CM, RIVERABUSTAMANTE RF (2003) Interactions between geminiviruses in a naturally occurring mixture: Pepper huasteco virus and Pepper golden mosaic virus. Phytopathology 93: 270-277.

MOFFAT AS (1999) Plant pathology - Geminiviruses emerge as serious crop threat. Science 286: 1835-1835.

MORALES FJ, ANDERSON PK (2001) The emergence and dissemination of whitefly-transmitted geminiviruses in Latin America - Brief review. Archives of Virology 146: 415-441.

MURRAY MG, THOMPSON WF (1980) Rapid Isolation of High MolecularWeight Plant DNA. Nucleic Acids Research 8: 4321-4325.

NOMBELA G, PASCUAL S, AVILES M, GUILLARD E, MUÑIZ M (2005) Benzothiadiazole induces local resistance to Bemisia tabaci (Hemiptera: Aleyrodidae) in tomato plants. Journal of economic entomology 98 2266-2271.

RENTERIA-CANETT I, XOCONOSTLE-CAZARES B, RUIZ-MEDRANO R, RIVERA-BUSTAMANTE RF (2011) Geminivirus mixed infection on pepper plants: Synergistic interaction between PHYVV and PepGMV. Virology Journal 8: 104.

ROJAS MR, HAGEN C, LUCAS WJ, GILBERTSON RL (2005) Exploiting chinks in the plant's armor: Evolution and emergence of geminiviruses. Annual Review of Phytopathology 43: 361-394.

SHEPHERD DN, MARTIN DP, THOMSON JA (2009) Transgenic strategies for developing crops resistant to geminiviruses. Plant Science 176: 1-11.

ŠINDELÁŘOVÁ M, ŠINDELÁŘ L, BURKETOVÁ L (2002) Glucose-6phosphate dehydrogenase, ribonucleases and esterases upon tobacco mosaic virus infection and benzothiodiazole treatment in tobacco. Biologia plantarum 45: 423-432.

THAKUR M, SOHAL BS (2013) Role of Elicitors in Inducing Resistance in Plants against Pathogen Infection: A Review. ISRN Biochemistry 2013: $1-10$.

TORRES-PACHECO I, GARZÓN-TIZNADO JA, BROWN JK, BECERRAFLORA A, RIVERA-BUSTAMANTE RF (1996) Detection and distribution of geminiviruses in Mexico and the Southern United States. Phytopathology 86: 1186-1192.

VANDERSCHUREN H, STUPAK M, FUTTERER J, GRUISSEM W, ZHANG P (2007) Engineering resistance to geminiviruses--review and perspectives. Plant Biotechnol J 5: 207-20.

VARMA A, MALATHI VG (2003) Emerging geminivirus problems: A serious threat to crop production. Annals of Applied Biology 142: 145-164.

WALTERS D, HEIL M (2007) Costs and trade-offs associated with induced resistance. Physiological and Molecular Plant Pathology 71: 3-17.

WHITHAM SA, YANG CL, GOODIN MM (2006) Global impact: Elucidating plant responses to viral infection. Molecular Plant-Microbe Interactions 19: $1207-1215$. 